\title{
Study of Relationship between Optimism, Pessimism and Coping Strategies with Mental Health among University Students of Lorestan
}

\author{
Simin Gholam Rezaei ${ }^{1}$, Sayed Sina Safari Mousavi1 ${ }^{*}$, Fatemeh Safari², Hamzeh Bahrami ${ }^{1}$, \\ Seyed Masoud Dehghan Menshadi ${ }^{1}$ \\ ${ }^{1}$ University of Lorestan, Khorramabad, Iran \\ ${ }^{2}$ University Azad of Hamedan, Hamedan, Iran \\ Email:"sinas900@gmail.com
}

Received 27 October 2015; accepted 26 December 2015; published 29 December 2015

Copyright (C) 2015 by authors and Scientific Research Publishing Inc.

This work is licensed under the Creative Commons Attribution International License (CC BY).

http://creativecommons.org/licenses/by/4.0/

(c) (i) Open Access

\section{Abstract}

The present study is conducted to determine the relationship between optimism, pessimism and coping strategies and mental health and ability to predict these concepts in students mental health in the academic year 2014 in Lorestan University. 367 subjects sampling via stratified random were selected among students of Lorestan University. Tools for data collection in this study are mental health questionnaire (GHQ-28), Life Orientation Test-Revised (LOT-R) and a questionnaire dealing with stressful situations (CISS). The method of study is correlational and data are analyzed using the stepwise regression. Data analysis shows that there are significant relationships among optimism, pessimism, and mental health $(p<0.01)$. There is positive and significant relationship between problem-oriented coping strategies and subject's mental health. Also there is a significant negative relationship between coping strategies and mental health $(p<0.01)$. The results of study show that optimism, pessimism, coping strategies and problem-oriented coping, differently explain variance related to mental health and its subscales significantly $(p<0.01)$. Generally speaking, optimistic people have more mental health because of following health lifestyles and behavior and confirming problem-oriented coping strategies. Those who follow have higher capacity of solving the problem, because they involve with the problem directly, so they have higher level of mental health.

\section{Keywords}

Optimism, Pessimism, Coping Strategies, Mental Health

\footnotetext{
${ }^{*}$ Corresponding author.

How to cite this paper: Rezaei, S.G., Mousavi, S.S.S., Safari, F., Bahrami, H. and Menshadi, S.M.D. (2015) Study of Relationship between Optimism, Pessimism and Coping Strategies with Mental Health among University Students of Lorestan. Open Journal of Social Sciences, 3, 190-195. http://dx.doi.org/10.4236/iss.2015.312021
} 


\section{Introduction}

World Health Organization (WHO) states that, health is a state of well-being that a person is in a state of complete physical, mental and social set. Mental health as a significant part of general health concept is the talent of creating harmonic relationship with others, the ability to participate in dynamic social environment and the talent of accepting effective changes. For achieving such precise goal, prevention of mental health problems, especially affective disorders, anxiety, depression, and evaluate the performance is essential [1]. Having mental health problems reduces people's ability in their tasks and motivations so they spend a significant portion of their intellect to solve those problems. As a result, these people haven't the ability and desire to do the assigned tasks [2].

Studies conducted by the World Health Organization show that 20 percent of Iranian people suffer from mental disorders and a case study conducted in Iran showed that 21 percent of people over 15 years old suffer from mental disorders. Studies have shown that factors such as coping strategies, problem-focused [3], optimism, sports [4], social capital, emotional intelligence and self-efficacy [5] have impact on the people mental health. However, any change in human life, both pleasant and unpleasant is requiring kind of compatibility. Procedures of coping with these changes and tensions resulting from these changes in different people and in different situations are different. Health Psychology gives great importance for the role of coping strategies on the physical and mental health. Coping strategy is a set of cognitive, behavioral and emotional effort which accomplish to interpret a stressful situation that includes: 1) Problem Oriented Strategies: Requires information about the situation and the consequences of its probable stress and delete and reform the stress-inducing situations; 2) Coping strategies: Requires finding ways to control the excitement and try for promising when deal with it; 3) Avoidance strategy: Requires deny or minimize stressful situations, dodge and play by ear [6].

One of the variables that seem to be related with mental health is optimism. Optimism is a cognitive construct that linked with motivation. The core of optimism is hope and positive expectation for the future, Regardless of whether or not the result will occur [7]. Optimism refers to two close concepts: the first concept is the tendency to hope and the second concept tendency to believe that we live in the best of all possible worlds [8]. Optimism has an important role in compatibility with major life events. Public consider optimism as (taking the glass half full) or tend to expect a happy ending for any trouble or as having a positive expect for outcomes and results. The opposite of optimism is pessimism that means an emphasis on the most catastrophic cause of the defeat and pessimism is a habit of mind that has disastrous consequences and for any defeat gets stronger. When optimistic people face with a challenge, they have stable state (even if progress is difficult or slow), but pessimistic are uncertain and unstable. Optimists believe that the adversity managed the successful way. But pessimists expect their misery. This difference in attitude towards adversity can affect the way of coping with stress. Generally optimistic people are more willing to use problem oriented strategies than pessimistic people [9]. Optimistic take advantage from the strategy that can be controlled by changing aspects of stressful factors, seeking information and planning, While pessimistic are used to strategies of play it by ear, withdrawal, denial and evasion or drug abuse [10]. According to the Scheier and Carver (1985) optimistic people believe that things are going in the right direction, but pessimists always expecting everything to go adversely and cause bad results [11]. Pessimistic experience high stress, regardless of ability to control the stressful situation and reduce stress, connected with the use of active and problem oriented and increased stress related to the use of avoidance and coping strategies [12]. Regard this issue; Ghazanfari Poor (2012) stated that there is a significant relationship between coping strategies and public health. This means that if individual use more Problem-oriented coping strategies, will has higher mental health [3]. Mousavi (2005) the relationship between optimism and strategies to cope with psychological adaptation in adolescents and showed that optimistic individuals use more Problem-oriented coping strategies [9]. The findings of Scheier et al. (1986) showed a positive correlation between optimism and problem-oriented coping strategy [13]. Iwanaga et al. (2004) investigated the relationship between optimism and pessimism and Concluded that optimistic people show less stress and high stress has positive correlation with pessimism. Carver and Scheier (2014) stated that there is a significant relationship between optimism and mental health [7]. Respect to the influence of environment on the behavioral characteristics of students due to new environments, and issues and problems in this new environment, including passing the exams, establishing of new relations of with which they are confronted, the purpose of this study was to investigate the relationship between optimism, pessimism and coping strategies and mental health in students of Lorestan University.

Research hypotheses: 
1) There is meaningful relationship between optimism with mental health in student's university of Lorestan?

2) There is meaningful relationship between coping strategies with mental health in student's university of Lorestan?

3) There is meaningful relationship between Problem-oriented coping strategies with mental health in student's university of Lorestan?

4) There is meaningful relationship between emotion-oriented coping strategies with mental health in student's university of Lorestan?

5) There is meaningful relationship between avoidance strategies with mental health in student's university of Lorestan

\section{Methods}

\subsection{Sampling}

The present study is quantitative and kind of correlation. The sample population of all male and female students of Lorestan University in the academic year 2014 all students were 8000 student that 367 subject were selected based on Morgan and Krejcie table. In this study stratified random sampling was used. Data collection tool was a questionnaire that prepared in two parts, one in demographic information and other questionnaire. Data collecting were from three public health Keldberg questionnaire (GHQ), for Life Orientation Test-Revised (LOT-R) and the Parker Coping Strategies Questionnaire (CISS).

\subsection{Mental Health Test (GHQ-28)}

To measure participant's mental health Kleberg questionnaire was used. This questionnaire is the most wellknown screening tools and designed in the form of 12, 28.30 and 60 questions. In this study 28 items were used in the four-point scale that was scored in $(0$ - 3). The questionnaire included 28 options $(1-7)$ the physical symptoms, options (8 - 14) Anxiety, options (15 - 21) social functions and options (22 - 28) to measure depression. To sum up the scores, a scores of zero, B 1, C 2, and D, 3 scores awarded. Scores Between 21 - 14, considered as an intensive disorder 13 - 7 as difficult and average and less than 6 as normal. The questionnaire has been validating via revision of the list of psychiatric symptoms (SCL90-R) and is a standard tool that Hooman (1998) in his study reported 83.0 internal consistency of the questionnaire. Also in this study, the validity coefficient of 82.0 is obtained [14].

Taghavi (2002) has calculated the questionnaire test-retest reliability coefficient with three ways, the test-retest, two halves and Cronbach's alpha, respectively, 0.70, 0.93 and 0.90 and reliability reported at the same time calculated 0.55 via questionnaire Middlesex [15]. Ghazanfari and Ghadampour (2012) reported the validity of this questionnaire 0.88 via Cronbach’s alpha [3].

\subsection{Life Orientation Test-Revised (LOT-R)}

This test is a short version of the test of life orientation test (LOT-R) of Scheier and Carver (1985), which measures optimism and pessimism individual differences and the subjects are asked to rate their agreement for any of the parts based on a Likert scale of 5 options of the zero (strongly disagree) to 4 (strongly agree). Its dimensions, including three for optimism 1, 4, 10 and three for pessimism 3, 7, 9 which is the inverse grading And four filling parts, which includes numbers 2-5-6-8 that are not grading, 6 scores are then added together and the obtained result can be between 0 and 24 and the closer to 24 is even more optimistic outlook. According to Akram and Ahmad (2011) the reliability of the questionnaire using Cronbach's alpha was calculated that obtained for optimism and 0.77 and pessimism 0.76 [16]. Also the divergence questionnaire was calculated to measure validity of test validity and the results showed that both optimism and pessimism have negative correlation with each other and the two are independent of each other and have discriminate validity.

\subsection{Questionnaire Coping with Stress and Stressful Situations CISS}

This questionnaire by Endler and Parker (1990) has been prepared and translated by Akbarzade in 1997 and consists of 48 parts that it covers three types of coping behavior. Deal with 1) problem oriented strategy; 2) Coping strategies; and 3) addressing the avoidance or evasion problem. The range encounter three types of be- 
havior like this: The score of confronting of each behavior is 16 to 80 and dominant way of dealing with the obtained grades in the test specified, it means that the higher a person's scores will be considered as coping behavior. Parker and Endler (1990) have reported 0.92 internal consistencies of the questionnaire and for the reliability of the questionnaire, used the Cronbach's alpha coefficient. The obtained counter of the problem oriented of boys emotion-oriented are 0.92 girls 0.85 , and Boys avoidance-focused style 0.82 and girls 0.85 and 0.85 , boys and girls avoidance-focused style 0.82 [6].

\subsection{Findings}

To analyze the data and test research hypotheses, correlation coefficient between variables were calculated. Pearson correlation test results are presented in Table 1 and Table 2.

\section{Conclusion \& Discussion}

The result of present study improves that there is a significant relationship between optimism and pessimism with mental health. This means that if more people viewing are optimistic about events, they will have higher mental health. Contrariwise, whatever one's view is pessimistic about what's going on, mental health is less. These findings of this study are the same vine with the results [7] [11] [12]. Conversano et al. (2010) stated that optimistic people have healthier lifestyle, better cognitive responses and adaptive behavior and mental health and higher flexibility of mental health than others [8]. Steptoe et al. (2006) observed that optimism is positively deal with healthy behaviors such as not smoking, drinking less alcohol, brisk walking and regular physical activity [17]. Optimistic people believe that things are generally going in the right direction and they emphasis on positive aspects of events, but Pessimistic expect things to go bad and bring negative results and emphasis on negative aspects and run bad feelings, optimists have higher quality of life style than pessimists [11]. Chang (2002), stated that comparison between pessimists and optimists shows that pessimists try to increase the negative

Table 1. Correlation coefficient between optimism and pessimism and strategies for coping with mental health and its subscales.

\begin{tabular}{cccccc}
\hline & $\begin{array}{c}\text { Physical } \\
\text { symptom }\end{array}$ & Anxiety & Social dysfunction & Depression & Mental health \\
\hline Optimism & 0.142 & $-0.291^{* *}$ & $-0.320^{* *}$ & $-0.471^{* *}$ & $-0.461^{* *}$ \\
Pessimism & $0.219^{*}$ & $0.335^{* *}$ & $0.197^{*}$ & $0.470^{* *}$ & $0.401^{* *}$ \\
$\begin{array}{c}\text { Problem-focused coping } \\
\text { strategies }\end{array}$ & -0.007 & $-0.307^{* *}$ & $-0.385^{* *}$ & $-0.329^{* *}$ & $-0.329^{* *}$ \\
$\begin{array}{c}\text { Emotion-focused coping } \\
\text { strategies }\end{array}$ & $0.447^{* *}$ & $0.458^{* *}$ & 0.105 & $0.483^{* *}$ & $0.484^{* *}$ \\
Avoidance coping strategies & -0.007 & -0.048 & -0.147 & -0.112 & -0.087 \\
\hline
\end{tabular}

${ }^{* *}$ Indicates a significant relationship at $\mathrm{p}<0.01$. $^{*}$ Indicates a significant relationship at $\mathrm{p}<0.05$.

Table 2. Correlation coefficient multiple correlation coefficients than F, regression coefficients and significant levels of mental health.

\begin{tabular}{|c|c|c|c|c|c|c|c|c|}
\hline \multirow{2}{*}{$\begin{array}{l}\text { Variable } \\
\text { criterion }\end{array}$} & \multirow{2}{*}{ Variable predictor } & \multirow{2}{*}{$\mathrm{R}$} & \multirow{2}{*}{$\mathrm{R}^{2}$} & \multirow{2}{*}{ R change } & \multirow{2}{*}{$\mathrm{F}$} & \multicolumn{3}{|c|}{ Regression } \\
\hline & & & & & & 1 & 2 & 3 \\
\hline \multirow{3}{*}{$\begin{array}{l}\text { Health } \\
\text { mental }\end{array}$} & $\begin{array}{l}\text { Emotion-focused coping } \\
\text { strategies }\end{array}$ & 0.484 & 0.232 & 0.232 & $39.68^{* *}$ & $\begin{aligned} B & =0.484 \\
t & =6.29\end{aligned}$ & & \\
\hline & $\begin{array}{c}\text { Emotion-focused \& } \\
\text { Problem-focused coping } \\
\text { strategies }\end{array}$ & 0.601 & 0.361 & 0.127 & $25.69^{* *}$ & $\begin{aligned} B & =0.503 \\
t & =7.14\end{aligned}$ & $\begin{aligned} B & =-0.357 \\
t & =-5.06\end{aligned}$ & \\
\hline & $\begin{array}{l}\text { Emotion-focused \& } \\
\text { Problem-focused coping } \\
\text { strategies \& optimism }\end{array}$ & 0.627 & 0.393 & 0.032 & $6.66^{* *}$ & $\begin{aligned} \mathrm{B} & =0.444 \\
\mathrm{t} & =6.21\end{aligned}$ & $\begin{array}{c}B=-0.281 \\
t=-0.375\end{array}$ & $\begin{array}{l}\mathrm{B}=-0.2 \\
\mathrm{t}=-2.51\end{array}$ \\
\hline
\end{tabular}

*** Indicates a significant relationship at $\mathrm{p}<0.01$. 
effect of stress on psychological adjust cognition so this cognition acts as vulnerable factor between stress and psychological adjustment [18]. Also in optimists we see a kind of behavior in which they tend to the health and reduce health danger. So dangers are considerable for optimists by choice not by excess [19].

The results of this study revealed a significant relationship between mental health and coping strategies; it means that, the more individual use coping strategies the more they have higher mental health and anxiety, show less social dysfunction and depression. Conversely, for person who follows emotion-oriented coping strategies more, mental health would be less. Also physical disorder, anxiety and depression will be more. In fact there's no meaningful relationship between avoidance coping strategies and mental health. These findings of this study are the same vein to the relationship between mental health and coping strategies with research results [3] [12] [20]. A significant relationship was observed in relation to the scale of mental health research in the field of depression, anxiety and social dysfunction problem-focused coping strategies. But there was no significant relationship of physical symptoms. Ghazanfari et al. (2012) did not find a significant relationship in the field of depression and anxiety and problem-focused coping strategies. The difference between the results of this study and Ghazanfari and Ghadampoor studies refers to difference between there coping strategies questionnaire, the type of the test and dissimilarity of situations [3]. Iwanaga et al. (2004) stated that people who used problem-oriented coping strategies have lower stress levels and the low levels of stress make kind of situations in which a person can uses dynamic cognitive skills in order to resistance the problems; therefore the person obtains more satisfaction, also they improve that reduction of stress is related to problem-oriented coping strategies [12]. It is observed that the problem-oriented coping strategies such as problem solving or information-seeking behavior and safe performance, such as higher capacity, better health are associated with positive performance [19]. Results of the present study revealed that there is a significant relationship between problems-oriented coping strategies, it means optimistic people use more problem-oriented strategies and conversely pessimistic people use more emotion-oriented and avoidance strategies. These findings are the same link to the study [11]-[13].

Iwanaga et al. (2004) observed that optimists have a large number of compatible plans and able to choose the appropriate situation. While pessimistic have immature plan and unstable so choices unstable and improper schedule and are under more tension [12]. Optimistic intended to emotional intelligence support, accept their role in creating the problem and are trying to rectify the situation and resist in front of problem but pessimistic desire to adaptation via obvious denial and mental and behavioral leave off from their goal.

Results of the present study revealed that there is a significant relationship between optimism, pessimism and problem-oriented coping strategies with mental health. Thus Optimistic have more mental health via using healthy behavioral and life style, have positive eye to the future, emphasis on positive aspect of events , not to be frustrated of defeats, confidence to their capability and talents and also using problem-oriented coping strategies. Those people using problem-oriented coping strategies, due to the direct involvement and confronting the issue as if the solve the problem properly, have more overcome and control on their environment, so they have more capability for appropriate planning and due to their high self-efficiency in solving the problem have more mental health. The limitation of this research was weakness in stating the relationship between cause and effect of variables.

\section{References}

[1] Karami, S. and Ashraf, P. (2001) Studying of Mental Health in Zanjan University of Medical Sciences. Journal of Zanjan University of Medical Sciences, 35, 9. (Persian).

[2] Adham, D., Salem, P., Mohammad, A. and Satari, Z. (2009) Considering the Mental Health of Students Entering Year 2008-2009 of Ardebil Medical Science University. Journal of Ardabil University of Medical Sciences, No. 4 (Persian).

[3] Ghazanfari, F. and Kadampoor, A. (2012) Considering the Coping Strategy and Mental Health in Residents of Khorramabad City. The Quarterly Journal of Fundamentals of Mental Health, 9, 37 (Persian).

[4] Sardar, M.A. and Sohrab, A. (2009) The Influence of Aerobic Exercise on Mental Health in Type 2 Diabetic Patients. Iranian Journal of Endocrinology and Metabolism, 11, 3. (Persian).

[5] Amini, M., Narimani, M., Sobhi, T. and Maleki, N. (2008) The Relationship between Emotional Intelligence, Self-Efficacy and Mental Health of Students in Gifted and Ordinary. Journal of Knowledge \& Research Applied Psychology, 10, 36. (Persian).

[6] Endler, N.S. and Parker, J.D.A. (1990) Multidimensional Assessment of Coping a Critical Evaluation. Journal of Personality and Social Psychology, 58, 5. http://dx.doi.org/10.1037/0022-3514.58.5.844 
[7] Carver, C.S. and Scheier, M.F. (2014) Dispositional Optimism. Trends in Cognitive Science, 118, 6.

[8] Conversano, C., Rotondo, A., Lensi, E., Vista, O.D., Arpone, F. and Redam, A. (2010) Optimism and Its Impact on Mental and Physical Well-Being. Clinical Practice and Epidemiology in Mental Health, 25, 6. http://dx.doi.org/10.2174/17450179010060100025

[9] Mousavi, M.H. (2005) The Relationship between Optimism and Pessimism and Coping Strategies and Predict Psychological Adjustment in Adolescents. Iranian Journal of Psychiatry and Clinical Psychology, No. 40. (Persian).

[10] Scheier, M.F., Mattew, S.K.A., Owen, S.J.F., Magovern, G.J., Abbot, R.A. and Carver, C.S. (1989) Dispositional Optimism and Recovery Coronary Artery Bypass Surgery the Beneficial Effect on Physical and Psychological Well-Being. Journal of Personality and Social Psychology, 57, 1024-1040.

[11] Scheier, M.F. and Carver, C.S. (1985) Optimism, Coping and Health: Assessment and Implication of Generalized Outcome Expectancies. Health Psychology, 4, 219-247.

[12] Iwanaga, M.Y., Yokoyama, H. and Seiwa, H. (2004) Coping Availability and Stress Reduction for Optimism and Pessimistic Individuals. Personality and Individual Differences, 36, 11-22. http://dx.doi.org/10.1016/S0191-8869(03)00047-3

[13] Scheier, M.F., Weintraub, J.K. and Carver, C.S. (1986) Coping with Stress Divergent Strategies of Optimist and Pessimist. Journal of Personality and Social Psychology, 51, 1257-1264.

[14] Hooman, A. (1998) Normal Access to Mental Health Questionnaire Graduate Students of Tarbiat Moallem University of Tehran, Educational Research Institute of Tehran University of Teacher Education. (In Persian)

[15] Taghavi, S.M. (2002) Consider the Validity and Stability of Keldberg Public Health Questionnaire on a Group of Shiraz University Students. Journal of Psychology, 15, 28 (In Persian)

[16] Akram, M. and Ahmad, A. (2011) The Relationship of Optimism and Pessimism with Mental Health of High School Students and Teacher in Kouhpaieh. Journal of Personality Psychology, 9, 3. (In Persian)

[17] Steptoe, A., Wright, C., Kunz, S.R. and Iliffe, S. (2006) Dispositional Optimism and Health Behavior in Community Dwelling People Association on Switch Healthy Ageing. Journal of Health Psychology, 11, 71-84.

[18] Chang, E.C. (2002) Optimism-Pessimism and Stress Appraisal: Testing a Cognitive Interactive Model Psychological Adjustment in Adults. Cognitive Therapy and Research, 26, 675-690.

[19] Snyder, C.R. and Lopez, J. (2002) Handbook of Positive Psychology. Oxford University Press, New York.

[20] Compas, B.E., Conner, J.K., Saltzman, H., Thomsen, A.H. and Wadsworth, M.E. (2001) Coping with Stress during Childhood and Adolescence Problem, Progress and Potential in Theory and Research. Psychological Bulletin, 127, 87127. http://dx.doi.org/10.1037/0033-2909.127.1.87 